\title{
A Proposed Approach to Investigate Whether Postgraduate Health Care Management Education in Australian Universities Facilitates the Development of Informatics Competencies
}

\author{
Mark BROMMEYER ${ }^{\mathrm{a}, 1}$, Mark MACKAY ${ }^{\mathrm{b}}$, Zhanming LIANG $^{\mathrm{b}}$, \\ Louise SCHAPER ${ }^{\mathrm{b}}$ and Peter BALAN ${ }^{\mathrm{b}}$ \\ ${ }^{a}$ Health Care Management, Flinders University, Australia \\ ${ }^{\mathrm{b}}$ University of South Australia, James Cook University, Australasian \\ Institute of Digital Health and University of South Australia
}

\begin{abstract}
Competencies have emerged as being important in healthcare. AIDH has health informatics competencies and ACHSM has health service management competencies but as health care is rapidly changing, it is important that the required competencies continue to evolve. The aim is to investigate whether postgraduate health care management education in Australian universities facilitates the development of informatics competencies. The proposed approach followed the NWCPHP 'Steps Used to Effectively Map Preexisting Courses to Competency Sets' to map the health informatics competency statements against the ACHSM accredited and RACMA recognised, postgraduate health care management programs offered domestically in Australia. The initial results show that only $10 \%$ of the AHICF competencies were fully addressed, $12 \%$ of the AHICF competencies were mostly addressed, $28 \%$ were partially addressed, and $50 \%$ of the AHICF competencies were not addressed at all. The proposed course competency mapping approach demonstrates that there is a need to revisit the informatics competencies taught in postgraduate health care management programs in Australia.
\end{abstract}

Keywords. Workforce, competency, nursing informatics

\section{Introduction}

The Fourth Industrial Revolution is upon us and we know that it "is broad and is characterized by a fusion of technologies across physical, digital and biological domains"[1]. In healthcare, this is having profound, transformational effects in the diagnosis, delivery and management of care due to the rapid speed of advances in genomic mapping, synthetic biology, nanotechnology engineering, big data, artificial intelligence and robotic automation.

${ }^{1}$ Corresponding Author, Mark Brommeyer, College of Business, Governmet and Law, Flinders Univeristy, GPO Box 2100 Adelaide SA 5001, Australia; E-mail mark.brommeyer@flinders.edu.au. 
Global forecasts emphasise that these new technologies and innovations have important workforce implications and will have far reaching implications for how we educate and train health care managers, so we must consider "how education will need to evolve for those entering the workforce as well as how to retrain the existing workforce to align with evolving technologies and labour trends" [1]. This needs to be reflected in the competencies health service managers require.

Competencies for Health Service Managers have been established by professional bodies (for example, the Australasian College of Health Service Management) [2] and researched by academics, including Laing, et al [3]. The range of competencies required by health service managers continues to evolve as the industry changes. This requires regular review of the competencies required to be demonstrated in the management of healthcare.

The Australasian Institute of Digital Health (AIDH) recognised the need for those working in health informatics to meet certain competencies [4]. To this end, a competency framework and a certification process was developed by its predecessor, the Health Informatics Society of Australia (HISA), to enable health informaticians to have their competencies recognised - the Australasian Health Informatics Competency Framework (AHICF). A competency is defined as the specification of knowledge and skill, and the application of that knowledge and skill, to the standard of performance expected in the workplace [5]. In the United Kingdom's National Health Service, it has been forecast that all areas of health service delivery will be affected by the adoption of digital technology and this will necessitate the upskilling of the workforce [6]. Given the rapid rate of progress in healthcare and informatics, there is a need to revisit the informatics competencies taught in postgraduate health care management programs.

The aim is to propose an approach to investigate whether postgraduate health care management education in Australian universities facilitates the development of informatics competencies. Part of the general aim will be achieved by gaining an understanding of what current educational programs are being provided in Australia. To this end, a starting point is the mapping of existing programs and this paper proposes an approach for this component of the overall research aim.

\section{Methods}

AHICF's fifty (50) health informatics competency statements have been mapped to the Australasian College of Health Service Management (ACHSM) accredited and the Royal Australasian College of Medical Administrators (RACMA)[7] recognised postgraduate health management programs offered domestically in Australia, by subject or course topic using content that is publicly available and able to be accessed or provided by the universities. The mapping process followed the 'Steps Used to Effectively Map Preexisting Courses to Competency Sets' approach, developed by the University of Washington School of Public Health's Northwest Center for Public Health Practice (NWCPHP), as this has demonstrated a high level of confidence in the accuracy of the process for mapping competencies to its courses [8].

The mapping process was undertaken to identify, collect, map and then validate the competencies, according to the NWCPHP's six step approach: 
1. Choose competency set(s) - the ACHSM Master Health Service Management Competency Framework and the Australian Health Informatics Competency Framework (AHICF).

2. Determine courses to be mapped - 21 post-graduate programs that were either accredited by ACHSM or recognised by RACMA.

3. Determine who does the mapping - an internationally experienced health informatics academic completed the initial mapping, with oversight provided by a health service management competency specialist, who is also a management competency researcher. The mapping was then independently validated by an expert health informatics competency specialist educator and a former head of a university business school.

4. Establish criteria for mapping - based on the Association of American Medical Colleges' Curriculum Management and Information Tool (CurrMIT) [9] a Competency Mapping Matrix spreadsheet was built to enter program names, subject or course topic learning objectives, and the fifty AHICF competencies. The programs were then reviewed by subject title, learning objectives and assessments for key words, competency indicators, and themes that matched with the competency framework. This was mapped on the spreadsheet as the degree to which the competency was seen as being addressed, using a four-point criteria scale: i) not addressed; ii) partially addressed; iii) mostly addressed; and iv) fully addressed.

5. Use reliability checking process - the Competency Mapping Matrix spreadsheet was piloted with one academic and one professional services university staff member to confirm the reliability and validity of the rating instrument. Interrater reliability of the competency mapping process and tool was used to establish the validity of the mapping itself.

6. Resolve outstanding disputes - any discrepancies were resolved by a subject matter expert, being an Australian Professor in Health Service Management.

\section{Results}

The RACMA recognised and ACHSM accredited listings of university master's level programs were accessed to provide the information about the health care management programs being offered domestically in Australia. Non-accredited or recognised programs were not considered.

It was found that there are 41Australian university-based master's level health management programs, and that:

- 17 programs were ACHSM accredited

- 14 programs were RACMA accredited

- 10 programs were accredited by both ASCHM and RACMA

- 21 were accredited by either ASCHM or RACMA (based on available online listings on ACHSM and RACMA websites)

The 50 AHICF health informatics competencies are across six competency domains: 1) Health Sciences (9 competencies); 2) Information Science (5 competencies); 3) Information Technology (3 competencies); 4) Leadership and Management (10 competencies); 5) Social and Behavioural Sciences (5 competencies); and 6) Core Health 
Informatics (18 competencies). The ACHSM 85 health service manager competencies are across five competency domains: 1) Leadership (12 competencies); 2) Health and Healthcare Environment (16 competencies); 3) Business Skills (32 competencies); 4) Communications and Relationship Management (12 competencies); and 5) Professional and Social Responsibility (13 competencies).

What the results show, is that of the 21 master's level programs mapped, only $10 \%$ of the AHICF competencies were fully addressed (all of the AHICF competency key words and the health informatics context was identified), $12 \%$ of the AHICF competencies were mostly addressed (two or more of the AHICF competency key words and the health informatics context was identified), $28 \%$ were partially addressed (two or more of the AHICF competency key words and no health informatics context was identified), and $50 \%$ of the AHICF competencies were not addressed at all (none of the AHICF competency key words and no health informatics context was identified).

\section{Discussion}

Internationally there is a growing body of literature around graduate health administration curricula and the need for health informatics competency development [10]. To ensure that we can best manage health care requirements, we need to harness the opportunities the Fourth Industrial Revolution provide us. In healthcare we need the required competencies in health informatics. Health care managers need to demonstrate contemporary and constantly evolving competency in the "knowledge and skill, and the application of that knowledge and skill, to the standard of performance expected in the workplace" [5].

Universities have responded to the need for those working in the health sector to become skilled in health informatics through the introduction of largely postgraduate level qualifications [11]. One of the pathways includes postgraduate health care management. The health care management pathway, however, while it provides limited specific health informatics education programs, does provide a well-rounded education (e.g., change management, financial management, etc.).

Given the changing nature of health informatics, it is important that the required competencies are able to be incorporated into existing and future Australian postgraduate health care management curricula. These informatics competencies will guide the workforce training and education developments into the future and will ensure that health care managers have the competencies required for the management of healthcare, for consumers, funders, governing and regulatory bodies assurance.

As Australia's largest health workforce, nurses and midwives have pivotal roles in the capture, creation, communication and use of clinical information. Accordingly, "the Digital Health Capability Framework for the Nursing and Midwifery Workforce has been created to define the knowledge, skills and attitudes required for professional practice in the digital health era" [12]. Importantly, the role of nursing management must also be underpinned by informatics competencies.

\section{Conclusion}

For health care practitioners interested in pursuing health care management studies, the majority of options in Australia are now at the postgraduate level. Given the rapid rate 
of progress in health care and informatics, there is a need to revisit the informatics competencies taught in postgraduate health care management programs.

We believe that the proposed course competency mapping approach demonstrates that this is indeed the situation in health care management courses in Australia. This is part of a larger research project designed to investigate whether postgraduate health care management education in Australian universities facilitates the development of informatics competencies.

The findings of this study will potentially have far reaching implications for how we educate and train health care managers. This needs to be reflected in the informatics competencies all health care managers require.

\section{References}

[1] World Economic Forum. Global Future Council on the Future of Health and Healthcare Report. World Economic Forum, Geneva Switzerland, 2019.

[2] Australasian College of Health Service Management. Master Health Service Management Competency Framework. ACHSM, Gladesville Australia, 2016.

[3] Liang Z, Short SD, Howard PF, Brown CR. Centralised control and devolved responsibilities: Personal experiences of senior health executives on the implementation of the area health management model in New South Wales, 1990-1999. Asia Pacific Journal of Health Management 1 (2016), 44-50.

[4] Health Informatics Society of Australia. Certified Health Informatician Australasia Competencies Framework. HISA, Melbourne Australia, 2013.

[5] Martin-Sanchez F, Rowlands D, Schaper L, Hansen D. The Australian Health Informatics Competencies Framework and its role in the Certified Health Informatician Australasia (CHIA) Program. Studies in Health Technology and Informatics 245 (2017), 783-787.

[6] Health Education England. NHS Topol Review: Preparing the healthcare workforce to deliver the digital future. Health Education England, London United Kingdom, 2019.

[7] Royal Australasian College of Medical Administrators. University Masters' Requirements. RACMA, Melbourne Australia, 2019. https://racma.edu.au/resources/medical-leadership-and-managementcurriculum/ accessed: 23 November 2019).

[8] Neiworth LL, Allan S, D’Ambrosio L, Coplen-Abrahamson M. Charting a course to competency: An approach to mapping public health core competencies to existing trainings. Health promotion practice, 15:1 (2014), 33S-38S.

[9] Al-Eyd G, Achike F, Agarwal M et al. Curriculum mapping as a tool to facilitate curriculum development: a new School of Medicine experience. BMC medical education, 18:1 (2018), 1-8.

[10] Williams KS, Harle CA, Vest J, Johnston A, Menachemi N. How and why Health Administration students should learn how to use HER. Journal of Health Administration Education, 35:4 (2018), 575585.

[11] Australasian College of Health Informatics. The ACHI Education Directory. Melbourne Australia, 2019. https://www.achi.org.au/education-directory/ (accessed: 24 November 2019).

[12] Australian Digital Health Agency. National nursing and midwifery digital health capability framework. ADHA, Sydney Australia, 2020. 